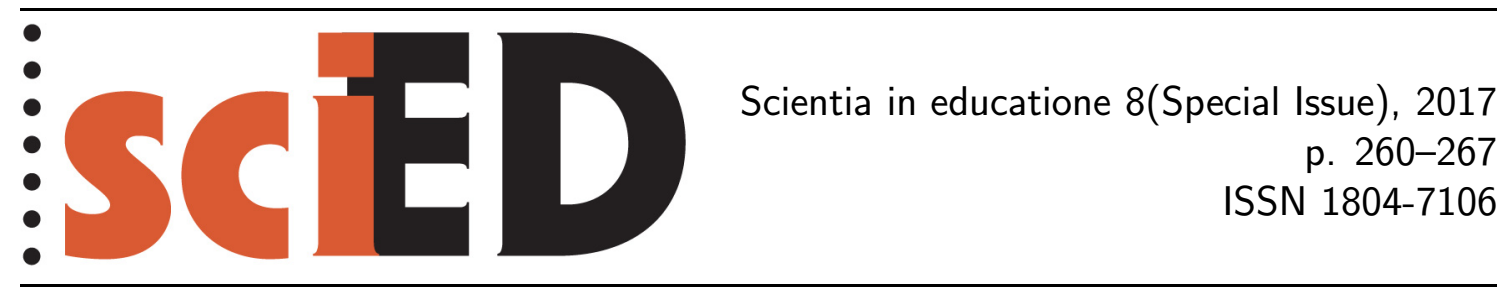

\title{
Embedding Formative Assessment and Promoting Active Learning
}

\author{
Elizabeth Swinbank, Mary Whitehouse, Robin Millar
}

\begin{abstract}
In this contribution we outline how the York Science project is using a 'backward design' approach to teaching science to students aged 11-14. We then present some examples of formative assessment tasks and show how simple selected-response questions can be modified to provide teachers with detailed information about students' ideas. Finally we indicate how such tasks can help promote active learning.
\end{abstract}

Key words: formative assessment, diagnostic questions, backward design. 


\section{InTRODUCTION: THE YORK SCIENCE PROJECT}

York Science (Millar \& Whitehouse, 2012) is a project based in the University of York, UK, which is developing a large package of resources to support the teaching of science to students age 11-14. The project's guiding principles are:

- What matters in science education is what students learn.

- The aim of teaching is to promote learning.

- We need to shift the focus from what is taught to what is learned:

- from activities to outcomes

- from the intended curriculum (what teachers teach)

- to the attained curriculum (what students actually learn)

A key component of the York Science resource package is a wide variety of assessment tasks and questions which can be embedded in normal classroom practice and provide evidence of successful learning, or of learning difficulties to which teachers can respond.

The positive impact of formative assessment on student learning has been well established, for example by Paul Black and Dylan Wiliam (1998a, 1998b). John Hattie's synthesis of over 800 meta-analyses (Hattie, 2008) identifies 'feedback' as one of the most effective interventions relating to student achievement. Hattie points out that feedback is most powerful when it is from the student to the teacher: "When teachers seek, or are at least open to, feedback from students as to what students know, what they understand, where they make errors, when they have misconceptions - then teaching and learning can be synchronised and powerful." (Hattie, 2008: p. 173).

However, teachers are not always aware of research evidence, and even if they are aware, they might not have the time or resources to reflect fully on its implications or to make appropriate changes to their practice. As Smith and Gorard (2005) showed, even though research indicates the benefits of formative feedback, it may not be implemented effectively.

The York Science project is drawing on the research findings to inform the development of resource materials, with the aim of helping science teachers to incorporate effective formative assessment into their teaching.

\section{YORK SCIENCE AND BACKWARD DESIGN}

The term backward design was used by Wiggins and McTighe (2005) to describe a process of curriculum design that puts the emphasis on student learning outcomes, rather than starting by developing student activities or focusing on the transmission of content.

Backward design is the process adopted by York Science. The first step is to decide what it is that we want students to learn — the Learning Intentions. To help us identify these for a chosen area of science, we begin by writing a progression that shows how knowledge and understanding can be built up over time through the development of increasingly sophisticated concepts. We start by listing the most basic ideas and observations that would be introduced to young children and continue some way beyond the level that would usually be reached by a fourteenyear-old student. This is similar in many respects to the approach described by 
Wilson (2009). Writing a progression draws on research evidence where available and typically requires several stages of drafting and redrafting.

Once the progression has been written, we identify the part that is appropriate for students in the 11-14 age range. We can then begin to write a framework for the York Science topic, starting with a concise narrative summarising the intended learning and a list of what we want students to know and understand - the Learning Intentions.

Next, we consider how we might find out whether the intended learning had taken place - what the Evidence of Learning might be. In order to elicit this evidence, we need to devise tasks and questions, which we call Evidence of Learning Items (ELIs). Only when the Leaning Intentions and ELIs are in place are we, and teachers, in a position to develop learning activities that focus on the Learning Intentions, and whose efficacy can be evaluated using the ELIs.

The process of developing the Learning Intentions and ELIs is iterative (Figure 1). In trying to specify the desired Evidence of Learning it sometimes becomes apparent that the Learning Intention needs to be modified because it is ambiguous, or inappropriate, or assumes some prior learning that we had not previously identified. Similarly, writing ELIs often helps to clarify the Intentions and the Evidence.

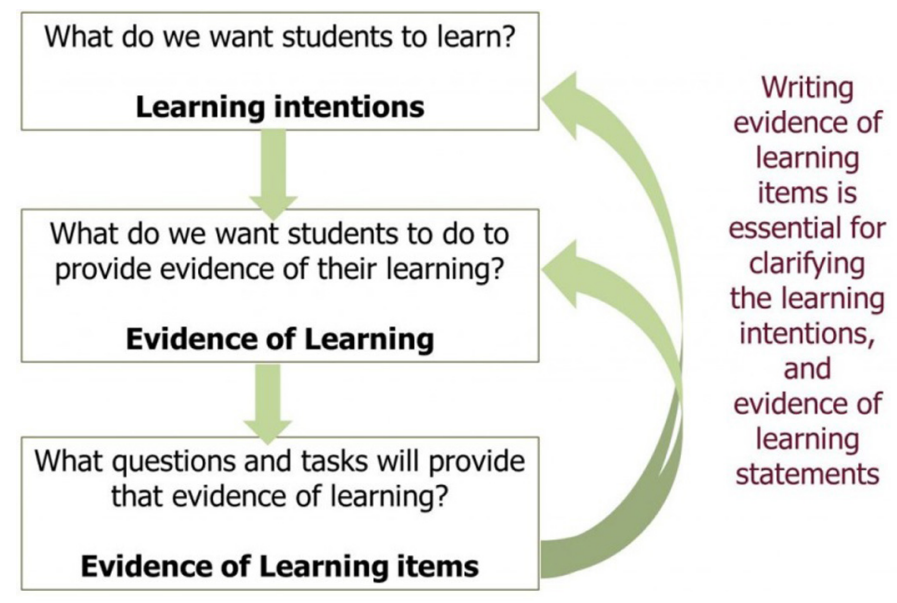

Figure 1: The York Science approach

\section{EVIDENCE OF LEARNING ITEMS (ELIs)}

The ELIs used by York Science include a wide variety of tasks, such as:

- predict the outcome of a practical task, then explain-observe-explain;

- discuss, evaluate and select alternative explanations for an observation;

- make a physical model (e.g. particles in a solid, a liquid and a gas);

- construct a concept map to show relationships between ideas;

- sort and select statements to produce an explanation or argument;

- free writing in response to a question or stimulus.

While many of the ELIs have been devised specifically for York Science, some are based on situations used in published assessment schemes such as the Force Concept Inventory (Hestenes, Wells \& Swackhamer, 1992), the Children's Learning in Science Project (1980-1989) and EPSE (Millar et al., 2006) projects, and the Assessment of Performance Unit (Black, 1990). 
A key feature of many York Science ELIs is that they are diagnostic. As well as showing the teacher whether a student has learnt what was intended, they provide evidence about how a student might be thinking and the alternative conceptions that they might hold. This feedback is immensely valuable to the teacher, who can then plan the next stage of teaching and learning in order to help the students make progress.

Many ELIs are presented as selected-response questions, as these provide feedback quickly and concisely. This can be done in a pencil-and-paper test, but there are other ways in which a teacher can gather feedback from a class; students can for example be asked to:

- stand in different areas of the classroom to indicate their chosen response;

- write the letter of their response on a small whiteboard and hold it up;

- use an electronic voting system.

However, a single selected response provides only limited information to the teacher, so the York Science team have been exploring ways of 'adding value' to such questions so as to elicit more information. Approaches used by York Science include:

- add a free-response question after the students have made their choice, asking them to explain their reasoning;

- add a second part that asks students to choose from some suggested explanations for their first answer.

In the latter case, the suggested explanations draw on research evidence about common misconceptions (for example, the incorrect idea that current diminishes around a simple series circuit, or that motion at constant velocity requires the action of an unbalanced force).

Another approach is to start with a simple multiple-choice question but ask students how sure they are that each response is right or wrong. Figure 2 shows an example. The correct answer is $\mathrm{D}$, but many people would choose one or more of $\mathrm{A}$, $\mathrm{B}$ or C. Asking students to use the grid in Figure 3 provides much more information than asking them to select a single response.

\section{What can you see in the dark?}

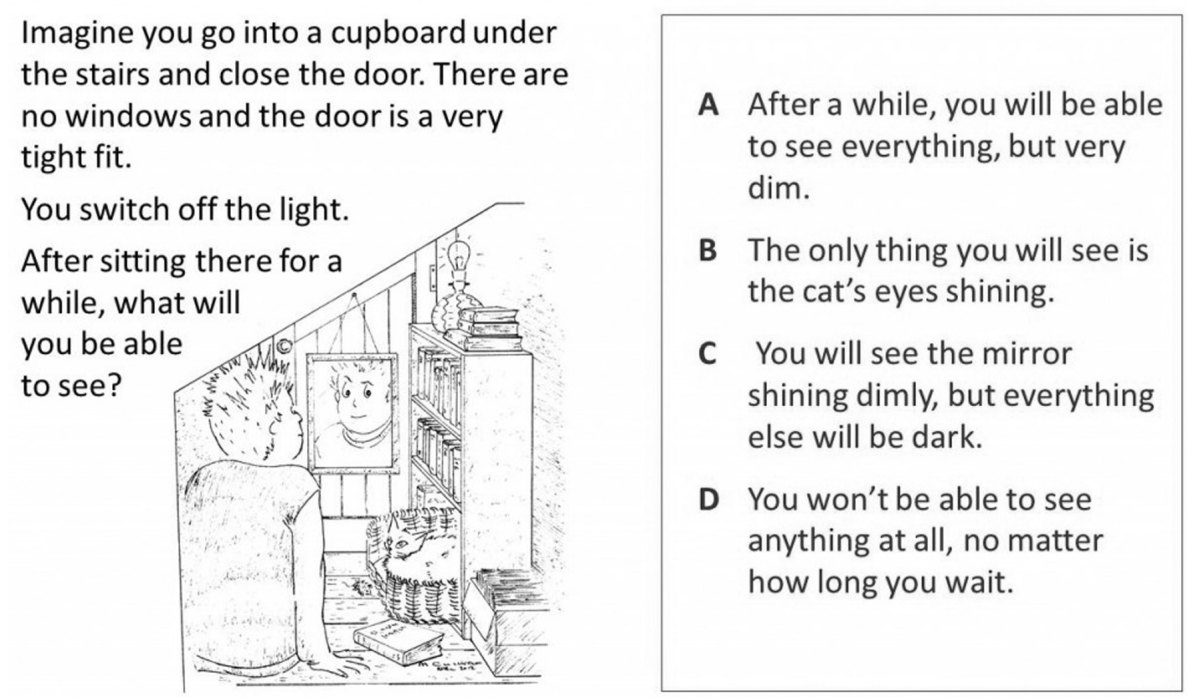

Figure 2: A York Science selected-response question from the Light and colour topic 


\begin{tabular}{|l|l|l|l|l|l|}
\hline \multicolumn{2}{|l|}{ Statement } & $\begin{array}{l}\text { I am sure } \\
\text { this is } \\
\text { right }\end{array}$ & $\begin{array}{l}\text { I think this } \\
\text { is right }\end{array}$ & $\begin{array}{l}\text { I think this } \\
\text { is wrong }\end{array}$ & $\begin{array}{l}\text { I am sure } \\
\text { this is } \\
\text { wrong }\end{array}$ \\
\hline A & $\begin{array}{l}\text { After a while, you will be able to see } \\
\text { everything, but very dim. }\end{array}$ & & & & \\
\hline B & $\begin{array}{l}\text { The only thing you will see is the cat's } \\
\text { eyes shining. }\end{array}$ & & & & \\
\hline C & $\begin{array}{l}\text { You will see the mirror shining dimly, } \\
\text { but everything else will be dark. }\end{array}$ & & & & \\
\hline D & $\begin{array}{l}\text { You won't be able to see anything at } \\
\text { all, no matter how long you wait. }\end{array}$ & & & & \\
\hline
\end{tabular}

Figure 3: Answer grid for use with the question in Figure 2

(A cupboard under the stairs seems to be a peculiarly British thing. Delegates at the conference discussed how the question in Figure 2 could be adapted for other nationalities by referring to other completely dark spaces such as a cellar, a bathroom without windows, an underground cave or a remote, unlit, rural location on a cloudy night.)

Another way to gather information about students' thinking is to allocate each student 100 points and ask them to distribute them between answers A, B, C and D. Tell them that they will score all the points that they give to the correct answer (or answers). For example, a student who is very confident might give 100 points to a single response, whereas someone who is undecided between two responses might give 50 points to each one.

Figure 4 shows another variation on the selected-response question. This item presents a sequence of choices and the selected responses build up an explanation, so the ELI tests understanding of the whole 'story' of how we see.

\section{USING ELIS}

The York Science project is encouraging teachers to use ELIs in a wide variety of ways, with regard to both when they are used and how they are used.

ELIs can be used:

- at the start of a lesson, or sequence of lessons, to assess students' prior knowledge and understanding;

- part way through a lesson, or sequence of lessons, to assess progress and to help the teacher plan what to do next;

- at the end of a topic, for summative assessment and to gauge the overall effectiveness of the teaching and learning.

While ELIs can be used by individual students to inform a teacher about their own learning, there are many more productive ways to use them with a class. Here are just a few of the ways that York Science teachers have used ELIs:

- Project the ELI onto a whiteboard. Ask students to indicate, by raising their hands, what they think is the correct response.

- Give the same ELI to each small group of 2-4 students. Ask them to discuss and decide what they think the answer should be. Tell them that each student should be able to explain their group's answer to the rest of the class.

- Instead of telling students the right answer, follow the ELI with a practical activity so that they can find out the answer for themselves. 
Imagine you are in a room lit by sunlight and you are looking at a book on the table.

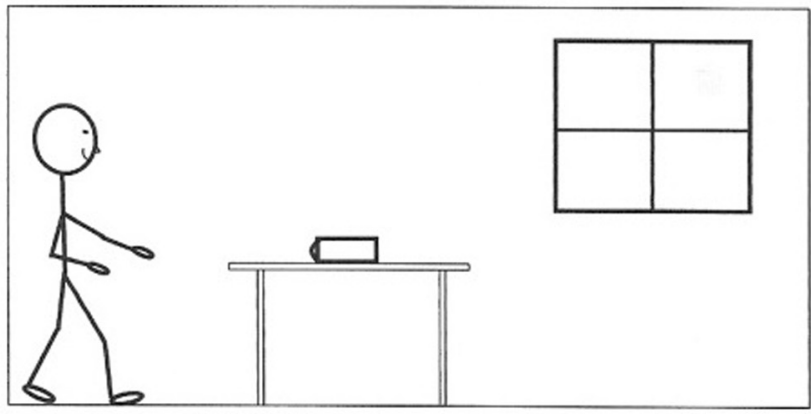

The statements in the boxes below link together to form an explanation of how you see the book.

Some boxes contain more than one statement. In each of these boxes, pick the statement that you think is correct and fits into the whole explanation. Indicate your choice by putting a line through the other statement(s) in the box.

Continue until you have chosen one statement from every box, to produce a complete scientific explanation for how you see the book.

\begin{tabular}{|c|c|}
\hline 1 & Light travels out in all directions from the Sun. \\
\hline 2 & Sunight passes through the window into the room. \\
\hline $3 a$ & Some of this light from the Sun falls on the book. \\
\hline $3 b$ & Some of this light from the Sun goes into my eyes \\
\hline $3 c$ & Sunlight fills the room and makes it bright. \\
\hline $4 a$ & Light is emitted by the book. \\
\hline $4 \mathrm{~b}$ & Light is scattered by the book. \\
\hline $4 c$ & Light is absorbed by the book. \\
\hline $5 a$ & As a result, some light travels from the book to my eyes. \\
\hline $5 b$ & At the same time, some light goes from my eyes to the book. \\
\hline $6 a$ & I see the book because it is lit up. \\
\hline $6 b$ & I see the book because this light enters my eyes. \\
\hline
\end{tabular}

Figure 4: Constructing an explanation 
- Display an answer grid (Figure 3) on a large flipchart or on a whiteboard. Give each student some Post-it stickers and ask them to place a sticker in their chosen cell for each response. After discussion and teaching, which might include practical work and demonstration, repeat the process.

As these suggestions illustrate, ELIs can lead naturally to active learning, where students are involved in discussing and refining their ideas, and in hands-on exploration. So, while the backward design approach focuses initially on outcomes and assessment, there is no clear dividing line between formative assessment and learning, and a task designed for assessment can be used as the starting point for actively engaging students in exploration of scientific concepts and principles.

Teachers are responding very positively to York Science and are seeing the benefits to their teaching, like this teacher who remarked "The materials have caused me to reconsider my approach to lesson planning, and have been an excellent aid."

It is particularly pleasing that teachers are using the York Science materials as a model for devising their own ELIs then sharing their ideas with the York Science project team and with other teachers. This is a comment from the teacher who thought of using Post-it stickers for 'What can you see in the dark?' (Figures 2 and 3) and went on to write her own similar ELIs for other topics:

"The students enjoyed the hubbub of getting four (what, miss, four EACH?) post-it notes and sticking them to the part of the board that represented their answer. A benefit of doing it like this is that you can get the class to stick up their responses, teach the lesson, then ask if they would like to change their answers making the process more of a demonstration of their progress and less of a snapshot of their misconceptions. Thank you twitter and York Science, I can see this idea being adapted for many, many lessons!"

\section{CONCLUSiON}

So far, York Science Learning Intentions and ELIs have been drafted for six topics two for each of physics, chemistry and biology (the physics topics addressed to date are Light and Colour and Electric Circuits). Each ELI is accompanied by notes for teachers which include a summary of relevant research evidence, for example highlighting common misconceptions.

More information about the project and samples of these materials are available from the 'Resources' pages of the York Science website. You can also subscribe to the York Science blog and follow us on Twitter to hear about new posts and updates. The aim is eventually to produce Learning Intentions and ELIs for all science topics commonly taught in the UK to students aged 11-14.

\section{REFERENCES}

Black, P. (1990). APU Science: The past and the future. School Science Review, $72(258), 13-28$.

Black, P. \& Wiliam, D. (1998). Assessment and classroom learning. Assessment in Education: Principles, Policy \& Practice, 5(1), 7-74.

Black, P. \& Wiliam, D. (1998).Inside the black box: Assessment for learning in the classroom. London: Kings College London. 
Children's Learning in Science Project (1980-1989). Resource archive. York: National STEM Centre. Available at

http://www.nationalstemcentre.org.uk/elibrary/collection/464/children-s-learning-inscience-project

Hattie, J. (2008). Visible Learning: A synthesis of over 800 meta-analyses relating to achievement. London: Routledge.

Hestenes, D., Wells, M. \& Swackhamer, G. (1992). Force concept inventory. The Physics Teacher, 30, 141-157.

Millar, R., Leach, J., Osborne, J. \& Ratcliffe, M. (2006). Improving subject teaching. Lessons from research in science education (Chapters 3 and 6). London: Routledge.

Millar, R. \& Whitehouse, M. (2012). The York Science Project - embedding assessment for learning. Education in Science (EiSXtra), 1-3. Available at http://yorkscience.org.uk/wp-content/uploads/2013/03/1211-YS-in-EiSxtra1.pdf

Smith, E. \& Gorard, S. (2005). 'They don't give us our marks': The role of formative feedback in student progress.Assessment in Education: Principles, Policy 83 Practice, 12(1), 21-38.

The York Science project website:

http://www.york.ac.uk/education/projects/yorkscience/

Wiggins, G. P. \& McTighe, J. (2005). Understanding by Design. Alexandria, VA: ASCD.

Wilson, M. (2009). Measuring progressions: Assessment structures underlying a learning progression. Journal of Research in Science Teaching, 46(6), 716-730.

ELIZABETH SWINBANK

MARY Whitehouse

ROBin MillaR

University of York, UK 